\title{
Evaluations of benzene impacts of a coke plant in a complex-topography urban area with the RAMS-CALMET-CALPUFF modelling system
}

\author{
V. Valdenebro, E. Sáez de Cámara, G. Gangoiti, L. Alonso, \\ J. A. García, J. L. Ilardia \& N. González \\ University of the Basque Country, Spain
}

\begin{abstract}
The RAMS-CALMET-CALPUFF modelling system, together with observations, has been used to analyse the benzene impacts of a coke plant located in a narrow river valley over a nearby urban area in the estuary of Bilbao. The initial aim of this study was to set up a methodology suitable for dispersion studies in very complex areas, where pollutant dynamics are highly affected by mesoscale processes. Emphasis was put on the validation and improvement of the simulated meteorology. High spatio-temporal resolution meteorological simulations were performed with the non-hydrostatic mesoscale meteorological model RAMS, initialized with NCEP reanalysis data, for two ten-day periods. Results were validated against data recorded both at surface stations and by a wind profiler radar (WPR). Comparisons against the WPR revealed inaccurate NCEP data for one of the periods. Alternative nudging with ECMWF ERA-Interim data improved the results. The RAMS output was downscaled from $1 \mathrm{~km}$ to $250 \mathrm{~m}$ resolution with the CALMET diagnostic model. The main flows that affect dispersion in the area were mostly well simulated, but important disagreements with observed drainage flows were found for some days. The assimilation of surface meteorological observations into CALMET, greatly improved the results. The meteorological fields were input into the CALPUFF non-steady-state puff dispersion model for dispersion simulations. The actual daily cycles of ground level benzene were well reproduced but concentration levels were underestimated. The availability of good meteorological observations in the area and good emission inventory has shown to be of prime importance.
\end{abstract}

Keywords: RAMS, CALMET-CALPUFF, near-field dispersion, complex topography, dispersion model, meteorological model. 


\section{Introduction: background, area description and objectives}

This paper shows an application of the CALPUFF system in the near-field in an area of complex topography in northern Spain. The potential impacts of benzene emissions from an old coke factory (PROFUSA) in the nearby urban area of Zorroza are analysed.

The town of Zorroza has been suffering pollution and odour episodes for years. Recent studies revealed high levels of several compounds that, even if they did not lead to violations of the regulations, they were occasionally high. An analysis of the wind data and volatile organic compounds (VOC), including benzene and naftalene, recorded in the area suggested that emissions from PROFUSA could be responsible for more than $70 \%$ of the high benzene levels registered in Zorroza [1].

Fig. 1 shows the study domain used for dispersion simulations: a mountainous region in a coastal area, with heights than range from sea level up to $1000 \mathrm{~m}$ and valleys with different orientations running into the sea. Zorroza is located at the confluence of the narrow, less than $500 \mathrm{~m}$ wide at its bottom, Cadagua valley (discharging into the Nervión valley following an S-to-N orientation) and the wider Nervión valley that discharges into the sea following a SE-to-NW orientation. The coke factory is located inside the Cadagua valley $1 \mathrm{~km}$ up the valley point of confluence with the Nervión River.

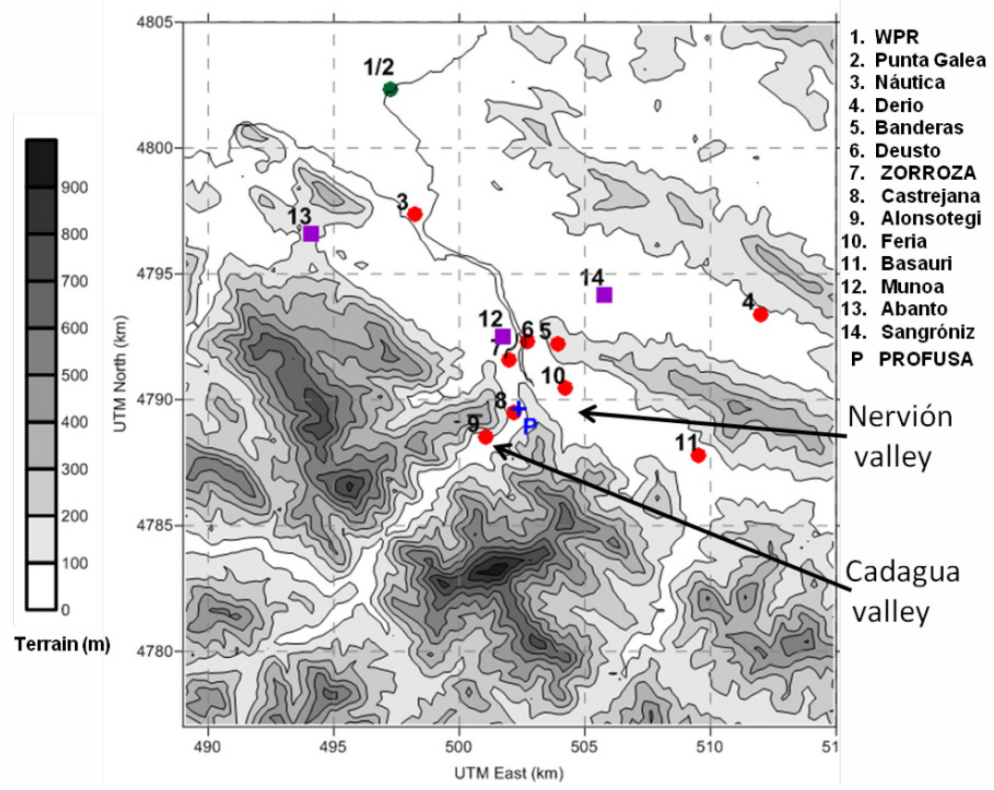

Figure 1: Study area. The location of the meteorological and air quality network and the WPR are shown. The coke factory (PROFUSA) is also included. 
Other sources of VOC as well as their ambient characterization were described by Durana et al. [2]. The details of the topography and a description of the mesoscale flows of the area, characterized by almost daily cycles of wind and stability, were already described by Millán et al. [3, 4] and Gangoiti et al. [5]. Land-to-sea drainage flows during the night usually precede up-slope and valley winds during the day. Channelling effects and coupling of in-valley flows with synoptically forced winds are also frequent in the area. The result is the occurrence of important and daily changes in stability, wind velocity and wind direction almost every day. These characteristics of the wind flow make the generalized use of steady-state Gaussian plume models inappropriate for this area $[4,6]$. The non-steady-state CALPUFF model is one of the United States Environmental Protection Agency (USEPA) recommended dispersion models for regulatory purposes [7]. This model is appropriate to be used on a case-by-case basis for studies in the near-field in complex terrain. Several studies [8,9] have been carried out to test the performance of CALPUFF in the near-field.

In this study, the impacts of PROFUSA benzene emissions in Zorroza during two selected periods were analysed using the RAMS-CALMET-CALPUFF modelling system. An stress was put in the improvement of the quality of the wind fields that fed CALPUFF, with the final goal of getting a more accurate representation of the dispersion conditions and eventually, of the simulated benzene concentrations fields. The results will help to set up a methodology to analyse dispersion and estimate impacts of pollutants in the study area.

\section{Selected periods and observational data}

Two ten-day periods were chosen for the study (from October 17th to 27th 2010, and from June 9th to 19th 2011) in order to analyse two different meteorological situations that characterize dispersion in the area under anticyclonic conditions during autumn and spring, the former having been shown to be the season for the occurrence of the most severe episodes of air pollution [3].

Meteorological variables are systematically recorded at a network of stations in the study area (fig. 1) with a temporal resolution of 10 minutes or 1 hour. Fig. 1 shows the 13 stations used for the present study. Hourly concentrations of benzene are also systematically recorded at two of them: Zorroza and Munoa. We will discuss the results at the former, where the higher benzene levels are usually registered where local residents' complaints about bad odours originating from PROFUSA are common. The high resolution data (30 minutes) of a WPR (fig. 1) are also available.

The analysis of the observational data shows that most of the benzene peak levels in Zorroza are concurrent with the Cadagua valley nocturnal drainage flows (fig. 2). These flows were registered almost every day during both periods. Then, a good simulation of these drainage flows is of key importance for an adequate estimation of the benzene concentrations originated from PROFUSA in the urban area of Zorroza. 
ZORROZA, JUNE 2011

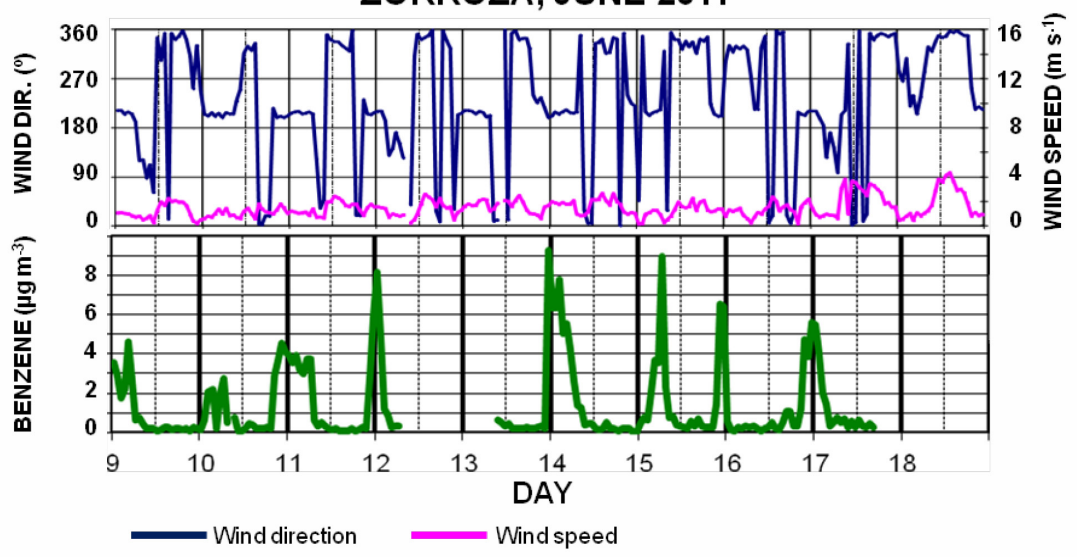

Figure 2: Time series of wind speed, wind direction and benzene levels at the Zorroza station for the 2011 analysed period.

\section{The modelling system}

In this study the RAMS model [10] was used for the simulation of the local meteorology, which was input into the CALMET-CALPUFF system [11, 12] for the dispersion evaluation (fig. 3). The interface code CALRAMS [13] was used to transform the three-dimensional meteorological data of RAMS into a CALMET-ready format.

RAMS had already been used in the area to reproduce the observed wind flows with high spatio-temporal resolution $[14,15]$. Version 4.4 was used in this study.

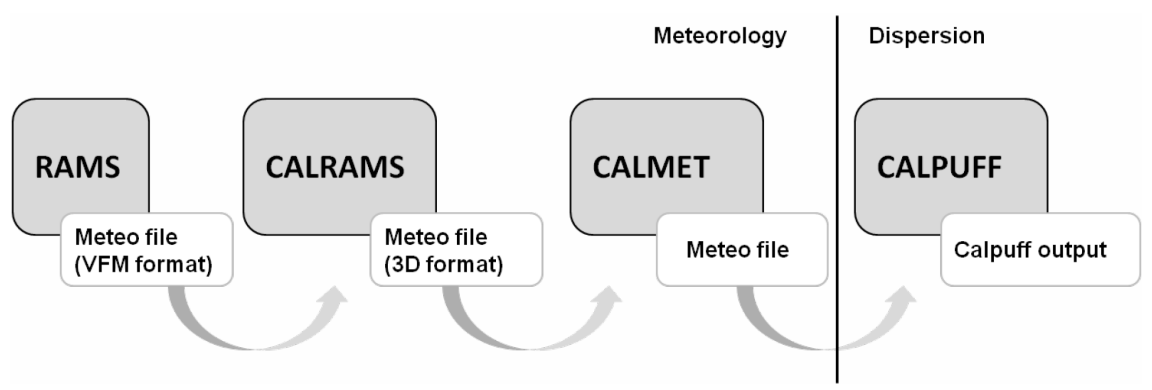

Figure 3: Main modules of the modelling system (grey boxes) and information flow (white boxes) between them.

The diagnostic meteorological model CALMET allows to be fed by prognostic models output. Thus, the prognostic model can be run with a significantly larger horizontal grid spacing and lower grid resolution than that 
used in the diagnostic model $[8,16]$, and to introduce into the diagnostic wind field results certain features of the flow fields that may not be captured in surface observational data. CALPUFF is a multi-layer non-steady-state puff dispersion model that can simulate the effects of temporally and spatially varying meteorological conditions on pollutant transport, transformation and removal.

Dispersion simulations are very sensitive to the meteorological fields used in their calculations. In this study, an emphasis was put in the assessment of the impact of alternative meteorological inputs in the estimation of benzene concentrations in the very complex terrain study area.

\subsection{RAMS setup and validation}

A configuration of four nested grids, with increasing resolutions of 48, 12, 3 and $1 \mathrm{~km}$, respectively, and centred in the Zorroza area was used (fig. 4). The dispersion study area is included in the finest resolution grid (grid 4); its resolution of $1 \mathrm{~km}$ is necessary to describe the local flows in the area. In the

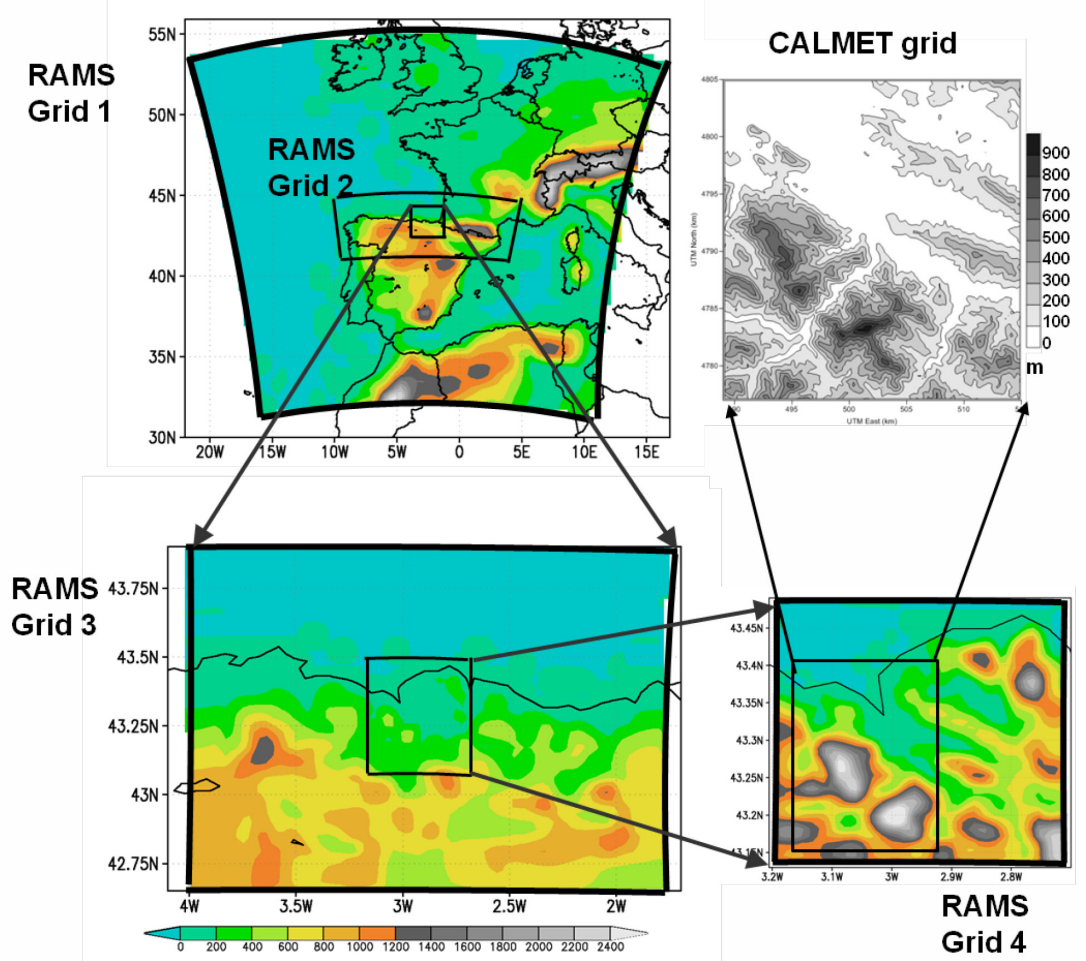

Figure 4: RAMS computational grids. Downscaling from the RAMS $1 \mathrm{~km}$ resolution grid 4 to the CALMET $250 \mathrm{~m}$ resolution grid is also shown. 
vertical, a total of 44 levels with variable resolution, the finest ones near the ground $(25-40 \mathrm{~m})$, were used up to a height of $22300 \mathrm{~m}$. A two-way nesting among the grids and a non-homogeneous initialization with non-stationary boundary conditions were used: four-dimensional data assimilation (FDDA) was used for the model run, nudging the boundaries and the center of the larger domain (grid 1) to the conditions given by the NCEP reanalysis_II daily data (2.5 latitude-longitude grid resolution; [17]) at 00:00, 06:00, 12:00 and 18:00 UTC. For the 2011 period, a second run was performed (see Section 4.1) using the European Center for Medium-Range Weather Forecasts (ECMWF) ERAInterim reanalysis data [18] for the nudging (the same gridded data with a $1.5^{\circ}$ resolution every six hours). Other initialization databases and procedures were similar to those described by Gangoiti et al. [14].

RAMS output was compared against the data recorded by the WPR and surface stations. Comparisons were performed both graphically and statistically, using standard metrics computed when checking the performance of models [19, 20]: bias (defined as simulated minus observed), root mean square error (rmse) and root mean square vectorial error (rmsve).

\subsection{CALMET setup and validation}

A domain of $26 \times 28 \mathrm{~km}$ with a horizontal resolution of $250 \mathrm{~m}$ and centred in the Zorroza area was used for the CALMET and CALPUFF simulations (fig. 4). In the vertical, 12 layers were used with the grid cells centred at the following heights above the ground: $10,60,147.5,255.5,406,586.5,827.5,1167,1868.5$, $3200.5,4737$ and $5966 \mathrm{~m}$.

Land uses and topography were downloaded from the CALPUFF website [21]. The SRTM3 topography, with an original resolution of $90 \mathrm{~m}$ was used.

For this study, CALMET was initialized with two different configurations. In the first one (configuration 1), the RAMS grid 4 output data were supplied as initial guess field for CALMET. In configuration 2 the RAMS data were supplied in the same manner, but an objective analysis was performed to combine them with the observations from a selection of 10 surface stations (indicated with circles in fig. 1); another 3 stations were kept out for validation tasks (stations indicated with squares in fig. 1).

Calmet output was also validated graphically and statistically. The validation of configuration 1 runs allowed us to elucidate if the wind adjustment to the finer topography performed by CALMET resulted in a significant improvement. The validation of configuration 2 simulations allowed us to evaluate the improvement in the meteorological fields after the assimilation of observational data into CALMET.

\subsection{CALPUFF: emission scenarios}

Annual benzene emission data were obtained from the most recent data of the Emissions Source Register by the Basque Government (E-PRTR) [22], from which a constant emission rate of $7.910^{-6} \mathrm{~g} \mathrm{~m}^{-2} \mathrm{~s}^{-1}$ was inferred considering continuous emissions uniformly distributed over the year and the plant surface. 
Two different emission scenarios were considered for each period, to account for the uncertainty in the emission effective height: a first scenario of surface emission (4 $\mathrm{m} \mathrm{agl})$ and a second scenario in which emissions were released at $30 \mathrm{~m}$ agl.

A comparison between registered and simulated benzene concentrations was performed for each scenario and meteorological configuration.

\section{Results}

\subsection{Meteorological simulations}

Comparisons of the simulations against the records of the WPR showed that RAMS adequately reproduced the main flows that affected dispersion in the area during the October 2010 experiment (not shown). However, during the June 2011 period important disagreements were found lasting for several days, as shown in fig. 5. Winds in the free troposphere (above 1000-1500 m) marked with a dotted line in the figure show better agreement between observations and simulations. Below that level, easterly winds (blue colors in the figure), associated with the reinforcement of the high pressures over the European continental mass, would be better simulated when nudging with ECMWF ERAInterim data (fig. 5c): although some differences (dotted open circles) are still evident, the NCEP-RAMS simulation was unable to generate these winds between 13-17 June.

The downscaling of RAMS output by CALMET also improved the simulated wind fields in the area (see table 1). However, important disagreements in the reproduction of the Cadagua valley drainage flow were revealed in the results of CALMET with configuration 1. Figure 6 shows the wind speed and direction at the Munoa station (near Zorroza and not assimilated into CALMET), together with the results of the CALMET simulations for the 2010 period. Although the run with configuration 1 captured some of the observed daily cycles, the southerly drainage of the Cadagua valley was not reproduced on some days (see days 17 and 24-25, in which the model established a northerly flow at surface, coupled with the wind aloft). On some other days $(18,19)$, the beginning of the drainage flow was delayed with respect to observations. The simulations for the June 2011 period fit the observations more adequately, although the Cadagua valley drainage would also start systematically later. Wind speed was overestimated in inner valley stations. Surface temperature was underestimated. Configuration 2 of CALMET greatly improved these results.

Statistical metrics reflected this improvement in the simulations results. Table 1 shows the statistical indices values for wind speed, wind direction and temperature for both analyzed periods at three stations: Zorroza (used to initialize the model), Munoa (not assimilated into CALMET and located near Zorroza) and Abanto (not assimilated and far from Zorroza; temperature is not registered at this station). 


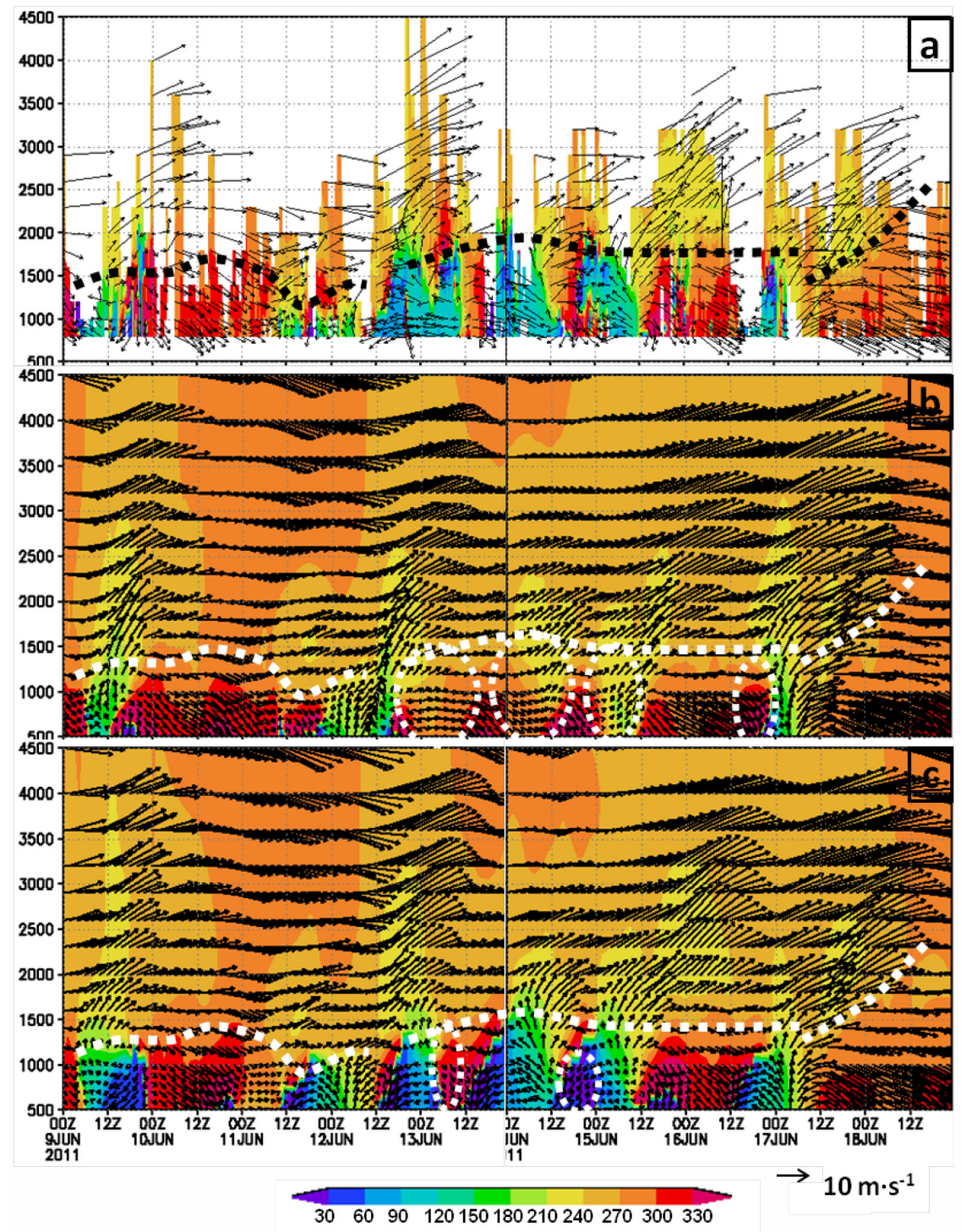

Figure 5: $\quad$ Time sequence of the (a) WPR observed winds (represented every 2 hours), and the simulated wind profiles on the vertical of the WPR for (b) RAMS-NCEP and (c) RAMS-ECMWF for the June 2011 period. 
MUNOA, OCTOBER 2010

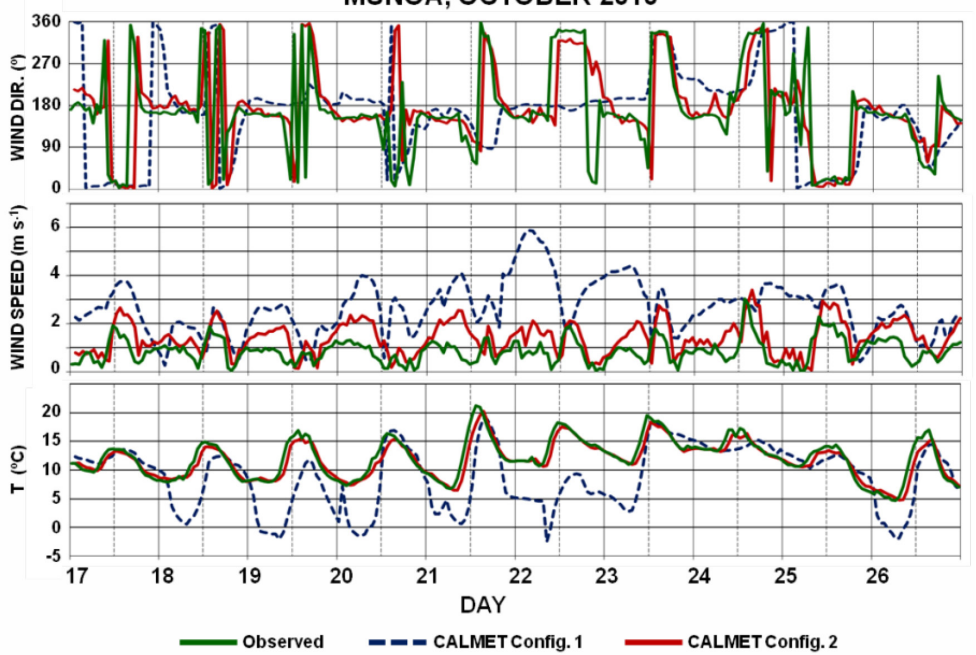

Figure 6: Wind speed, wind direction and temperature observed and simulated by CALMET with configurations 1 and 2 at the Munoa station (not assimilated into CALMET) for October 2010.

Table 1: $\quad$ Statistical indices at the Zorroza, Munoa and Abanto stations for the two simulated periods and for 3 different simulations: RAMS, and RAMS-CALMET with configurations 1 and 2.

\begin{tabular}{|c|c|c|c|c|c|c|c|}
\hline & & \multicolumn{3}{|c|}{2010 period } & \multicolumn{3}{c|}{ 2011 period } \\
\hline Index & MODEL & Zorroza & Munoa & Aban. & Zorroza & Munoa & Aban. \\
\hline u_mb $\left(\mathrm{m} \mathrm{s}^{-1}\right)$ & RAMS & $-0,42$ & $-0,22$ & $-0,27$ & 0,47 & 0,49 & $-1,68$ \\
\hline & RC_Conf.1 & $-0,10$ & 0,10 & $-0,15$ & 0,04 & -0.001 & $-1,61$ \\
\hline & RC_Conf.2 & $-0,09$ & $-0,19$ & $-0,38$ & 0,07 & 0.49 & $-1,49$ \\
\hline u_rmse $\left(\mathrm{m} \mathrm{s}^{-1}\right)$ & RAMS & 1,74 & 1,53 & 2,60 & 1,19 & 1,11 & 2,91 \\
\hline & RC_Conf.1 & 1,07 & 1,02 & 2,38 & 0,88 & 0.78 & 2,88 \\
\hline & RC_Conf.2 & 0,19 & 0,68 & 2,24 & 0,20 & 0.99 & 2,55 \\
\hline v_mb $\left(\mathrm{m} \mathrm{s}^{-1}\right)$ & RAMS & 0,52 & 0,96 & 0,03 & $-0,9$ & $-0,62$ & $-0,02$ \\
\hline & RC_Conf.1 & 0,32 & 0,74 & 0,04 & $-0,66$ & -0.41 & 0,2 \\
\hline & RC_Conf.2 & $-0,02$ & 0,35 & 0,41 & $-0,02$ & 0.14 & 0,16 \\
\hline v_rmse $\left(\mathrm{m} \mathrm{s}^{-1}\right)$ & RAMS & 2,78 & 2,81 & 2,36 & 2,09 & 2,08 & 1,37 \\
\hline & RC_Conf.1 & 2,38 & 2,30 & 1,96 & 1,46 & 1.42 & 1,13 \\
\hline & RC_Conf.2 & 0,09 & 1,02 & 1,49 & 0,07 & 0.64 & 0,96 \\
\hline u-v_rmsve $\left(\mathrm{m} \mathrm{s}^{-1}\right)$ & RAMS & 3,28 & 3,20 & 3,51 & 2,41 & 2,36 & 3,21 \\
\hline & RC_Conf.1 & 2,61 & 2,52 & 3,08 & 1,71 & 1.62 & 3,1 \\
\hline & RC_Conf.2 & 0,21 & 1,02 & 2,69 & 0,21 & 1.18 & 2,73 \\
\hline temp_mb $\left.{ }^{\circ} \mathrm{C}\right)$ & RAMS & $-2,93$ & $-2,85$ & --- & 2,20 & $-2,41$ & --- \\
\hline & RC_Conf.1 & $-3,22$ & $-3,40$ & --- & $-2,69$ & -2.93 & --- \\
\hline & RC_Conf.2 & $-0,06$ & $-0,41$ & --- & $-0,19$ & -0.7 & --- \\
\hline temp_rmse $\left({ }^{\circ} \mathrm{C}\right)$ & RAMS & 6,02 & 5,61 & --- & 3,23 & 3,38 & --- \\
\hline & RC_Conf.1 & 5,35 & 5,30 & --- & 3,51 & 3.70 & --- \\
\hline & RC_Conf.2 & 0,24 & 0,63 & --- & 0,30 & 0.78 & --- \\
\hline
\end{tabular}




\subsection{Dispersion simulations}

The progressive improvement in the simulation of the drainage flow of the Cadagua valley led to an improvement in the reproduction of the benzene impacts from PROFUSA in the Zorroza station. Figure 7 shows the results for 3 different runs for the June 2011 period: CALMET with configuration 1 fed with RAMS-NCEP, and CALMET with configurations 1 and 2 fed with RAMSECMWF.

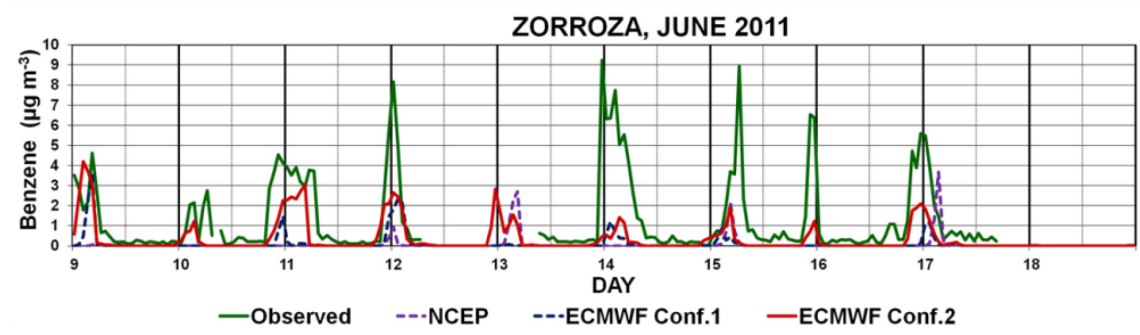

Figure 7: Simulated benzene concentrations at the Zorroza station (surface emission scenario). Results for 3 different runs are shown together with observations.

It was the surface emission scenario that gave concentrations closer to the observed ones, but the concentrations were clearly underestimated. For both periods it was the configuration 2 simulation that reproduced more adequately the daily cycles of benzene. In contrast to configuration 1, all nighttime and morning peaks of benzene were captured.

Fig. 8 shows the ground level concentration fields of benzene at selected times of the 16-17 June, 2011. The change of direction in the plume according to the reversal of the wind flow can be observed: in the evening of the 16th the pollutants are observed impacting inside the Cadagua valley within the coupled sea breeze and valley flow winds; then, at night, the plume reversed direction and the main impacts were moved into the Nervión valley following first the Cadagua S-to-N drainage flow and then the SE-NW direction of the Nervión valley. At this time, important benzene impacts are registered in Zorroza.

\section{Conclusions}

The RAMS-CALMET-CALPUFF modelling system has been implemented in an area of complex topography to investigate the capability of such a system to reproduce mesoscale circulations and their effect on the transport and dispersion of air pollutants in the area. During the process, an emphasis was put in the improvement of the simulated meteorological fields.

The importance of the availability of good observational data to validate the models was substantiated. Some inconsistencies were found in the NCEP 
Reanalysis data for one of the two simulated periods. Initializing the RAMS model with ECMWF-ERA-Interim data led to a more accurate representation of the observed wind fields. The downscaling of the RAMS output with CALMET also improved the simulated meteorological fields. So did the assimilation of observations into the system, which is of key importance to adequately reproduce the Cadagua valley drainage and the daily mesoscale flow dynamics.

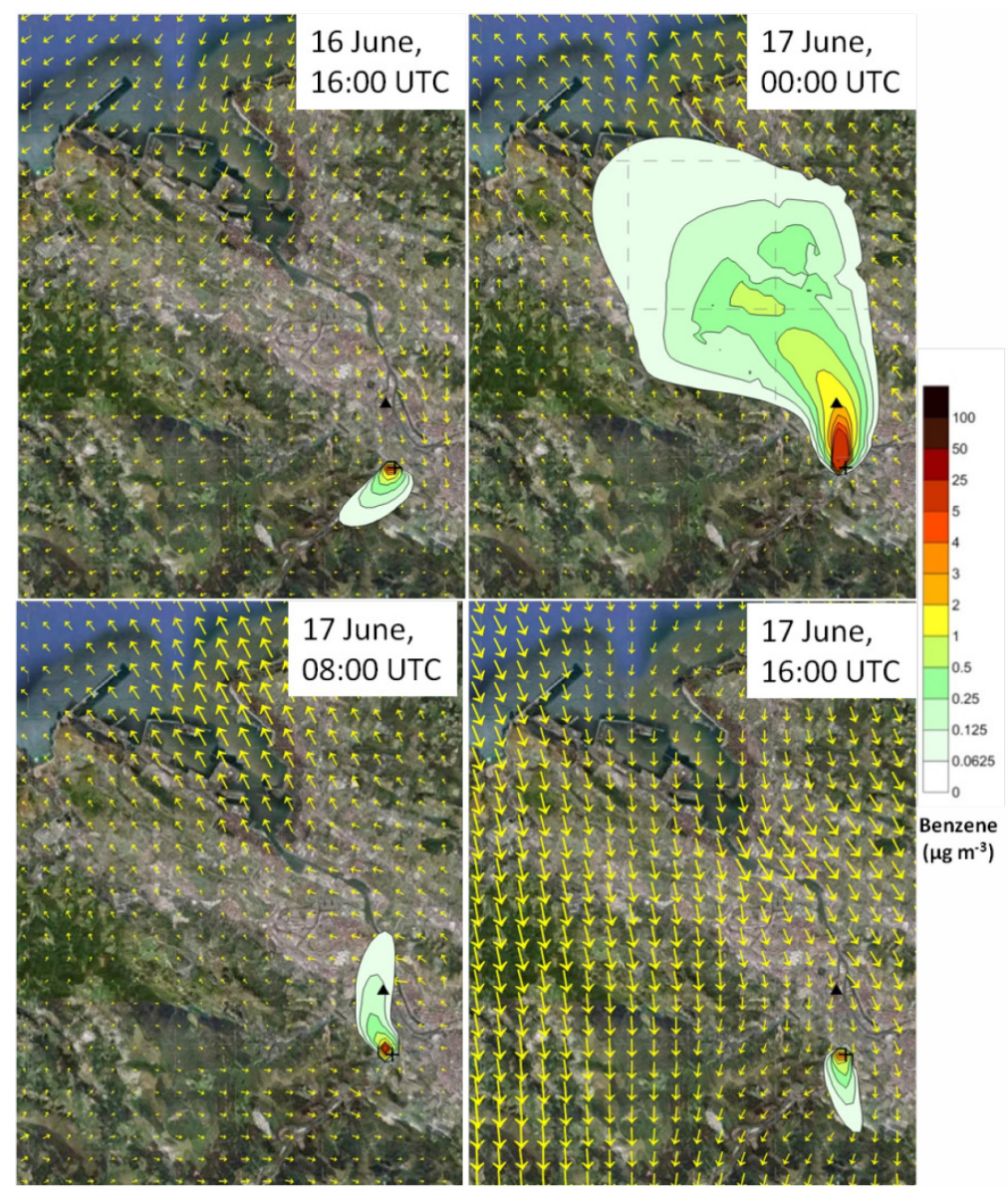

Figure 8: Mean hourly benzene concentrations simulated by CALPUFF (surface emissions scenario) at four instants of the June 2011 period. PROFUSA and Zorroza have been indicated with a cross and a triangle, respectively.

The hourly occurrence and main daily cycles of the benzene concentrations at the Zorroza station were well reproduced by using the emissions from the main source (PROFUSA) at surface level, but the actual concentrations were clearly 
underestimated. This could be caused by an underestimation of the registered benzene emissions.

\section{Acknowledgements}

The authors wish to thank the Viceconsejería de Medio Ambiente of the Basque Government for their support and the supply of complementary meteorological and air quality data. We also thank the Meteorological Service of the Basque Government for providing the WPR data.

\section{References}

[1] Uria, I., Gómez, M.C., Navazo, M., Durana, N., Gangoiti, G., de Blas, M., Valdenebro, V. and Elcoroaristizabal, S., Benzene and naphthalene as key gas markers in source apportionment of industrial sources in an urban atmosphere over complex terrain. Proc. of the 2nd Urban Environmental Pollution Conference, Amsterdam, 2012.

[2] Durana, N., Navazo, M., Gómez, M. C., Alonso, L., García, J. A., Ilardia, J. L., Gangoiti, G. and Iza, J., Long term hourly measurement of 62 nonmethane hydrocarbons in an urban area: Main results and contribution of non-traffic sources. Atmospheric Environment, 40, pp. 2860-2872, 2006.

[3] Millán, M. M., Alonso, L., Legarreta, J. A., Albizu, M. V., Ureta, I. and Egusquiaguirre, C., A fumigation episode in an industrialized estuary: Bilbao, November 1981. Atmospheric Environment, 18, pp. 563-572, 1984.

[4] Millán, M. M., Otamendi, E., Alonso, L. A. and Ureta, I., Experimental Characterization of Atmospheric Diffusion in Complex Terrain with LandSea Interactions, JAPCA, 37, pp. 807-811, 1987.

[5] Gangoiti, G., Alonso, L., Navazo, M., Albizuri, A., Pérez-Landa, G., Matabuena, M., Valdenebro, V., Maruri, M., García, J.A. and Millán, M. M., Regional transport of pollutants over de Bay of Biscay: analysis of an ozone episode under a blocking anticyclone in west-central Europe. Atmospheric Environment, 36, pp. 1349-1361, 2002.

[6] Lyons, W. A., Pielke, R. A., Tremback, C. J., Walko, R. L., Moon, D. A. and Keen, C. S., Modeling impacts of mesoscale vertical motions upon coastal zone air pollution dispersion. Atmospheric Environment, 29 (2), pp. 283-301, 1995.

[7] U.S. Environmental Protection Agency, Guideline on Air Quality Models, CFR, Part 51, Title 40, Appendix W, 2005.

[8] Cui, H., Yao, R., Y., Xu, X., Xin, C. and Yang, J., A tracer experiment study to evaluate the CALPUFF real time application in a near-field complex terrain setting. Atmospheric Environment, 45, pp. 7525-7532, 2011.

[9] Dresser, A. L. and Huizer, R. D., CALPUFF and AERMOD model validation study in the near field: Martis Creek revisited. Air \& Waste Management Association, 61, pp. 647-659. 
[10] Pielke, R. A., Cotton, W. R., Walko, R. L., Tremback, C. J., Lyons, W. A., Grasso, D., Nicholls, M. E., Moran, M. D., Wesley, D. A., Lee, T. L. and Copeland, J. H., A comprehensive meteorological modelling system RAMS. Meteorology and Atmospheric Physics, 49, pp. 69-91, 1992.

[11] Scire, J. S., Robe, F. R., Fernau, M. E. and Yamartino, R. J., User's Guide for the CALMET Meteorological Model (Version 5), Earth Tech. Inc., Massachusetts, 2000.

[12] Scire, J. S., Strimaitis, D. G. and Yamartino, R. J., User's Guide for the CALPUFF Meteorological model (Version 5), Earth Tech. Inc., Massachusetts, 2000.

[13] Earth Tech. Inc., (eds). Development of the Next Generation Air Quality Models for Outer Continental Shelf (OCS) Applications. Final Report: Volume 2 - CALPUFF Users Guide. (CALMET and Preprocessors), Massachusetts, 2006.

[14] Gangoiti, G., Albizuri, A., Alonso, L., Navazo, M., Matabuena, M., Valdenebro, V., García, J.A. and Millán, M. M., Sub-continental transport mechanisms and pathways during two ozone episodes in northern Spain. Atmospheric Chemistry and Physics, 6, pp. 1469-1484, 2006.

[15] Valdenebro, V., Gangoiti, G., Albizuri, A., Alonso, L., Navazo, M., García, J.A., Iza, J. and Millán, M. M., Build-up and decay of two ozone episodes through northern Iberia and southern France - An inter-regional transport analysis. Atmospheric Environment, 45, pp. 1591-1603, 2011.

[16] New Jersey Department of Environmental Protection (eds). CALPUFF Modeling Analysis of the Sulfur Dioxide and PM-2.5 Impacts due to Emissions from the Portland Generating Station, New Jersey, 2009.

[17] Kanamitsu, M., Ebisuzaki, W., Woollen, J., Yang, S. K., Hnilo, J. J., Fiorino, M. and Potter, G. L., NCEP-DOE AMIP-II Reanalysis (R-2). Bull. Am. Meteorol. Soc., 83, pp. 1631-1643, doi: 10.1175/BAMS-83-11-1631, 2002.

[18] Dee, D. P., Uppala, S. M., Simmons, A. J., and 33 more authors, The ERAInterim reanalysis: configuration and performance of the data assimilation system. Quarterly Journal of the Royal Meteorological Society, 137, pp. 553-597, doi: 10.1002/qj.828, 2011.

[19] Carvalho, J. C., Anfossi, D., Castelli, S. T. and Degrazia, G. A., Application of a model system for the study of transport and diffusion in complex terrain to the TRACT experiment. Atmospheric Environment, 36, pp. 1147-1161, 2002.

[20] Cox, R., Bauer, B. L. and Smith, T., A Mesoscale Model Intercomparison. Bulletin of the American Meteorological Society, 79 (2), pp. 265-283, 1998.

[21] ASG at TRC. Official CALPUFF Web Site, http://www.src.com/calpuff /calpuff1.htm

[22] Registro Vasco de Emisiones y Fuentes Contaminantes 2009; Departamento de Medio Ambiente, Planificación Territorial, Agricultura y Pesca, Gobierno Vasco. http://www.eper-euskadi.net/ 